\title{
Collagen cross-linking: when and how? A review of the state of the art of the technique and new perspectives
}

\author{
Leonardo Mastropasqua
}

\begin{abstract}
Since the late 1990s corneal crosslinking (CXL) has been proposed as a new possibility to stop progression of keratoconus or secondary corneal ectasia, with the promising aim to prevent progressive visual loss due to the evolution of the pathology and to delay or avoid invasive surgical procedures such as corneal transplantation. The possibility of strengthening corneal tissue by means of a photochemical reaction of corneal collagen by the combined action of Riboflavin and ultraviolet A irradiation (UVA), radically modified the conservative management of progressive corneal ectasia. This is a review of the state of the art of $C X L$, reporting basic and clinical evidence. The paper describes basic principles, advantages and limits of different CXL techniques and possible future evolution of the procedure.
\end{abstract}

Keywords: Keratoconus, Ectasia, Collagen cross-linking, Transepithelial cross-linking, Collagen corneal cross-linking epithelium off, Collagen corneal cross-linking epithelium on, Transepithelial cross-linking with iontophoresis

\section{Introduction}

Corneal ectasia is a progressive corneal thinning associated with alterations of stromal collagen matrix resulting in irregular protrusion of the cornea. Primary forms include keratoconus, pellucid marginal degeneration and keratoglobus, while secondary forms are mainly related to refractive surgery [1].

Many studies on keratoconus epidemiology from different countries reported an incidence of 1.3 to 22.3 per 100 000 and a prevalence of 0.4 to 86 cases per 100000 [2].

The incidence of corneal ectasia after refractive surgery is still unknown, but it has been estimated to be 0.04-0.6 \% after laser in situ keratomileusis(LASIK) [3-5].

Post LASIK ectasia represents about $96 \%$ of all secondary ectasias after refractive surgery, while $4 \%$ are related to photorefractive keratectomy (PRK) surgery [6].

Keratoconus generally starts during the second decade of life with a variable rate of progression of corneal steepening that continues until the fourth decade, when the corneal shape generally becomes stable [7].

\footnotetext{
Correspondence: mastropa@unich.it

Ophthalmology Department, Policlinico SS Annunziata, Center of Excellence and National High-Tech Center (CNAT) in Ophthalmology, University "G.
} d'Annunzio" of Chieti-Pescara, Via dei Vestini, 3166100 Chieti, Italy
A conservative approach in the management of keratectasia initially involves spectacles and subsequently, contact lenses.

However, surgical intervention can be necessary when patients are contact lens intolerant or cannot achieve adequate vision correction. In patients with contact lens intolerance or poor visual recovery with contact lens use, implantation of intracorneal rings (ICRS) may improve the regularity of the corneal curvature, improving contact lens fitting and visual rehabilitation [8].

Alternatively, in advanced stages or in presence of central corneal scarring, corneal transplantation may represent the only viable treatment option [1]. In these cases the preferred procedure is deep anterior lamellar keratoplasty (DALK) or, alternatively, penetrating keratoplasty (PK).

Until recently, in the "pre-CXL era", all of the treatment options for corneal ectatic diseases were aimed at only overcoming refractive limitations and not to impeding the underlying physiopathology [9].

Corneal crosslinking has grown from an interesting concept to its introduction in clinical practice in the late 1990s when it radically modified conservative management of progressive corneal ectasia with the possibility of strengthening corneal tissue [10]. 


\section{Review}

\section{Basic principles of corneal crosslinking}

The primary aim of corneal crosslinking is to stop the progression of corneal ectasia. To obtain a strengthening of corneal tissue, the use of riboflavin is combined with ultraviolet A irradiation (UVA). Riboflavin plays the role of a photosensitizer in the photopolymerization process and when combined with UVA irradiation, increases the formation of intrafibrillar and interfibrillar carbonyl-based collagen covalent bonds through a molecular process that has still not been completely elucidated [1].

It was shown that during the early aerobic phase of the process of crosslinking, riboflavin molecules are excited to a single or triplet state and stromal proteins undergo a photosensitized oxidation via interaction with reactive oxygen species [11]. During the second anaerobic phase, when oxygen is depleted, corneal stroma interacts with reactive species of radical ions. This photochemical reaction results in an increase of corneal rigidity, of collagen fiber thickness and of resistance to enzymatic degradation, with consequent decrease of stromal swelling and permeability maximally, above all in the anterior stroma [12].

\section{Basic research results}

Currently, the photochemically induced effect of CXL in the cornea cannot be evidenced directly by staining methods or microscopic techniques. However, CXL induces several changes to collagen-containing tissue, from which indirect signs of the cross-linking effect can be deduced [9]. In fact, stress-strain measurements performed on human and porcine corneas documented an increased corneal rigidity after CXL treatment. The firming effect seems to be more evident in corneas with higher collagen content and in older tissue [13, 14]. Moreover, it has been reported that porcine crosslinked corneas showed a reduced tendency to swelling and hydration when compared to untreated controls [15]. Ex vivo studies on corneas of humans and rabbits indicated an increase of collagen fibers thickness after CXL treatment $[16,17]$. Results of basic research studies showed that CXL procedure improve the corneal resistance to degradation processes mediated by pepsin, trypsin and collagenase with lengthening of the turnover time of the collagen [18].

\section{Indications for CXL}

Not every cornea with keratoconus needs to undergo crosslinking. The main aim of CXL is to stop the progression of corneal ectasia, consequently the best candidates for this treatment are patients suffering from primary or post refractive surgery ectasia with documented progression of the disease. Although the criteria to classify ectasia as progressive have not been defined, changes in refraction, uncorrected visual acuity (UCVA), best-corrected visual acuity (BCVA), and topographical parameters are to be included. To date, published clinical studies indicated that CXL was used in cases of progression over a well-defined time period. In many reports, progression was defined as an increase in Kmax of 1 diopter (D) in 1 year, or a change in either myopia and/or astigmatism $\geq 3 \mathrm{D}$ in 6 months, a mean central K-reading change $\geq 1.5 \mathrm{D}$ observed in three consecutive topographies in 6 months, or a mean central corneal thickness decrease $\geq 5 \%$ in three consecutive tomographies in the previous 6 months. Contraindications to undergoing standard CXL treatment are the presence of corneal thickness of less than 400 microns, prior herpetic infection, severe cornea scarring or opacification, history of poor epithelial wound healing, severe ocular surface disease, history of immune disorders, and pregnancy/breast-feeding [19-21].

\section{Standard procedure and clinical results}

The standard Dresden protocol, as initially described by Wollensask et al. includes initial epithelial removal, the application of $0.1 \%$ riboflavin solution for $30 \mathrm{~min}$ followed by $30 \mathrm{~min}$ of UVA irradiation with a wavelength of $370 \mathrm{~nm}$ and power of $3 \mathrm{~mW} / \mathrm{cm}^{2}\left(5.4 \mathrm{~J} / \mathrm{cm}^{2}\right)$ [22].

A list of publications reporting the clinical results of traditional CXL procedures is shown in Table 1 [23-65]. In the last few years, several prospective and retrospective studies with a considerable follow-up period documented the effectiveness of the standard procedure in halting the progression of primary and secondary corneal ectasia, and in many cases, with an improvement of visual performance and topographical indexes.

Most of the reports about clinical outcomes of standard epi-off CXL are prospective or retrospective case series. In the follow-up after treatment, the main parameters evaluated are the maximal keratometry $\left(\mathrm{K}_{\max }\right)$ and the best corrected visual acuity (BCVA). The follow-up periods ranged between one and six years. All authors reported stabilization or flattening of corneal keratometry and stabilization or improvement of visual acuity after standard epi-off procedure.

The small number of randomized controlled trials may affect the interpretation of these results. However, the results reported by Wittig-Silva et al. (2015) of 100 eyes with a three-year follow-up constitute an important milestone that confirms the effectiveness of epi-off technique in stabilizing keratoconus progression [35].

\section{Limits and complications of standard procedure Treatment failure}

Treatment failure that occurs in 8.1-33.3 \% of the cases is usually defined as continued progression with an increase in maximum $\mathrm{K}$ readings of $1.0 \mathrm{D}$ over the preoperative value [66]. 
Table 1 Outcomes reported in literature for standard epi-off CXL procedures (2010-2015)

\begin{tabular}{|c|c|c|c|c|c|c|c|c|}
\hline \multirow[t]{2}{*}{ Author (Year) } & \multirow[t]{2}{*}{ Follow-up } & \multicolumn{4}{|c|}{ Results } & \multirow[t]{2}{*}{ Type of Study } & \multirow[t]{2}{*}{ Number of Eyes } & \multirow[t]{2}{*}{ Indication } \\
\hline & & Kmax & $\mathrm{K} 1 / \mathrm{K} 2$ & $\begin{array}{l}\text { Mean } \\
\text { Keratometry }\end{array}$ & BCVA & & & \\
\hline Lang S et al. (2015) [23] & 3 years & $\mathrm{D}$ & & & - & RCS & 29 & Keratoconus \\
\hline Poli M et al. (2015) [24] & 6 years & $S$ & & & 1 & PCS & 36 & Ectasia \\
\hline Di Bernardo M et al. (2015) [25] & 2 years & D & & & I & PCS & 57 & Keratoconus \\
\hline McAnena L et al. (2015) [26] & 3 years & S & & & I & RCS & 25 & Pediatric Keratoconus \\
\hline Sedaghat M et al. (2015) [27] & 1 year & S & & $\mathrm{D}$ & I & PCS & 97 & Keratoconus \\
\hline Khan WA (2015) [28] & 3 years & D & & & I & PCS & 71 & Keratoconus \\
\hline Yildirim A et al. (2014) [29] & 42 months & $\mathrm{D}$ & & & 1 & RCS & 20 & Post LASIK ectasia \\
\hline Kymionis GD et al. (2014) [30] & 5 years & & $\mathrm{D}$ & & I & PCS & 25 & Keratoconus \\
\hline Kumar Kodavoor S (2014) [31] & 1 year & $S$ & & & I & RCS & 24 & Pediatric Keratoconus \\
\hline Viswanathan D et al. (2014) [32] & 20 months & & $\mathrm{D}$ & & $S$ & PCS & 25 & Pediatric Keratoconus \\
\hline Goldich I et al. (2014) [33] & 3 years & S & & & $\mathrm{S}$ & PCS & 17 & Keratoconus \\
\hline Steinberg J et al. (2014) [34] & 2 years & $\mathrm{D}$ & & & I & PCS & 20 & Keratoconus \\
\hline Wittig-Silva C et al. (2014) [35] & 3 years & $\mathrm{D}$ & & & I & $\mathrm{RCT}$ & 100 & Keratoconus \\
\hline Elbaz U et al. (2014) [36] & 1 year & & & $S$ & $\mathrm{~S}$ & PCS & 9 & Radial Keratotomy \\
\hline Ghanem RC et al. (2014) [37] & 2 years & $\mathrm{D}$ & & & । & PCS & 42 & Keratoconus \\
\hline Toprak I et al. (2013) [38] & 1 year & $\mathrm{D}$ & & & I & RCS & 59 & Keratoconus \\
\hline Hashemi H et al. (2013) [39] & 5 years & $\mathrm{D}$ & & & I & PCS & 40 & Keratoconus \\
\hline Richoz O et al. (2013) [40] & 2 years & $\mathrm{D}$ & & & I & RCS & 26 & Post LASIK/PRK ectasia \\
\hline Ivarsen A et al. (2013) [41] & 22 months & D & & & $\mathrm{S}$ & RCS & 22 & Keratoconus \\
\hline Legare ME et al. (2013) [42] & 2 years & $\mathrm{S}$ & & & $S$ & RCS & 39 & Keratoconus \\
\hline O'Brart (2013) [43] & $4-6$ years & & & S & $\mathrm{S}$ & RCS & 30 & Keratoconus \\
\hline Arora R et al. (2012) [44] & 12 months & & & & I & PCS & 15 & Pediatric Keratoconus \\
\hline Chatzis N et al. (2012) [45] & 3 years & S & & & I & RCS & 59 & Pediatric Keratoconus \\
\hline Vinciguerra R et al. (2013) [46] & 4 years & $\mathrm{D}$ & & & I & RCS & 400 & Keratoconus \\
\hline Viswanathan D et al. (2013) [47] & 14 months & $\mathrm{D}$ & & & I & PIS & 76 & Keratoconus \\
\hline Poli M. et al. (2013) [48] & 3 years & S & & & S & PC & 55 & $\begin{array}{l}\text { primary and secondary } \\
\text { ectasia }\end{array}$ \\
\hline Lamy R et al. (2013) [49] & 2 years & $\mathrm{D}$ & & & 1 & PC & 68 & Keratoconus \\
\hline Kranitz K et al. (2012) [50] & 1 year & & $\mathrm{D}$ & & I & PC & 40 & Keratoconus \\
\hline Guber I et al. (2013) [51] & 1 year & S & & & 1 & PCS & 33 & Keratoconus \\
\hline Vinciguerra P et al. (2012) [52] & 2 years & & $\begin{array}{l}\text { K1 S/ } \\
\text { K2 D }\end{array}$ & & 1 & PCS & 40 & Pediatric Keratoconus \\
\hline Caporossi A et al. (2012) [53] & 3 years & & $\mathrm{D}$ & & 1 & PCS & 152 & Pediatric Keratoconus \\
\hline Goldich I et al. (2012) [54] & 2 years & $\mathrm{D}$ & & & 1 & PCS & 14 & Keratoconus \\
\hline Asri D et al. (2011) [55] & 1 year & $\mathrm{S}$ & & & S & PCS & 142 & Keratoconus \\
\hline Fuentes-Paez G et al. (2012) [56] & 6 months & & & S & 1 & PCS & 7 & Ectassia post RK \\
\hline Kymionis GD et al. (2012) [57] & 1 year & & & S & S & PCS & 14 & Keratoconus \\
\hline Koller T et al. (2011) [58] & 1 year & $\mathrm{D}$ & & & S & PCS & 151 & Keratoconus \\
\hline Greenstain SA et al. (2011) [59] & 1 year & $\mathrm{D}$ & & & S & $\mathrm{RCT}$ & 71 & $\begin{array}{l}\text { Primary and secondary } \\
\text { ectasia }\end{array}$ \\
\hline Raiskup F et al. (2011) [60] & 1 year & S & & & $\mathrm{S}$ & RCS & 32 & Keratoconus \\
\hline Hersh P et al. (2011) [61] & 1 year & S & & & 1 & RCT & 71 & Keratoconus \\
\hline Salgado JP et al. (2011) [62] & 1 year & S & & & S & PCS & 22 & Post LASIK ectasia \\
\hline
\end{tabular}


Table 1 Outcomes reported in literature for standard epi-off CXL procedures (2010-2015) (Continued)

\begin{tabular}{|c|c|c|c|c|c|c|c|}
\hline Caporossi A et al. (2010) [63] & 4 years & $\mathrm{D}$ & & I & PCS & 44 & Keratoconus \\
\hline Vinciguerra P et al. (2009) [64] & 2 years & D & & । & PCS & 28 & Keratoconus \\
\hline Vinciguerra P et al. (2010) [65] & 1 year & & D & I & PCS & 13 & Post LASIK/PRK ectasia \\
\hline
\end{tabular}

$S=$ Stabilized, $D=$ Significantly decreased, $I=$ Significantly improved, $P C S=$ Prospective case series, $R C S=$ Retrospective case series, $R C T=$ Randomized controlled trial, $P I S=$ Prospective interventional study, $P C=$ Prospective comparative

Poli et al. recently reported a failure rate of $11 \%$ during a follow-up period of six years. Keratoconus worsening was considered if patients presented an increase of more than 0.1 in $\operatorname{logMAR}$ uncorrected and best corrected visual acuity and/or an increase of keratometric values by more than $0.75 \mathrm{D}$ during the follow-up [24].

After standard CXL procedure, corneal haze is a relatively common complication reported by $10-90 \%$ of patients. However, to date the etiology and the natural course of clinical corneal haze after epi-off procedure has not been clearly defined $[67,68]$. In vivo confocal microscopy showed an increased stromal reflectivity associated to edema and keratocyte activation mainly evident 3-6 months after treatment, while in the late postoperative period, anterior and intermediate stromal layers showed a reduction of cellular density and fibrosis of extracellular matrix [69].

Several cases of infective keratitis following CXL treatment have been described including bacterial, protozoal, herpetic, and fungal keratitis [70].

The rare serious adverse events following traditional CXL that have been reported included diffuse lamellar keratitis at LASIK interface, corneal melting and persistent corneal edema due to endothelial failure [71-73].

\section{Introduction of epi-on technique}

The diffusion process of riboflavin in the stroma is limited by corneal epithelial tight junctions [74, 75], but epithelial debridement is considered the cause of the most important complications after CXL treatment such as intraoperative and postoperative pain, infective keratitis and abnormal wound-healing response [76, 77]. Riboflavin penetration through the epithelium can be increased by different strategies such as changing the physicochemical properties of the riboflavin molecule by adding chemical enhancers in the riboflavin formulation [78] or performing a mechanical disruption of corneal epithelium [79]. An in vivo confocal microscopy study reported that by increasing the duration of riboflavin application up to two hours, the obtained depth of CXL effect is similar to that achieved with standard epi-off technique [80].

Although the complication rate in patients treated with transepithelial CXL was reported to be low [69], so was the effectiveness of this technique (Table 2) [81-89]. Thus, its utility is still a matter of debate.

\section{Iontophoresis}

A novel approach to enhance riboflavin penetration is based on iontophoresis, a non-invasive system aimed to enhance the delivery of charged molecules into tissues using a small electric current [90]. Riboflavin, in the formulation used for iontophoresis, is negatively charged. It has been shown that an iontophoresis imbibition lasting five minutes achieves a sufficient riboflavin concentration in the corneal stroma for CXL treatment, with the advantage of shortening the imbibition time while preserving epithelial integrity [9].

Numerous ex vivo studies confirmed the effectiveness of iontophoresis imbibition in obtaining an adequate riboflavin concentration into the stroma and the induction of important biomolecular and structural modifications of corneal tissue [90-92]. Ex vivo biomechanical studies on rabbit and human cadaveric corneas showed that transepithelial crosslinking with iontophoresis imbibition induced an increase of the biomechanical resistance of human cornea comparable to that obtained with the standard crosslinking procedure [93, 94].

Preliminary clinical results of iontophoresis assisted corneal CXL are promising. The technique halts keratoconus progression without significant complications (Table 3) [95-97] however, longer follow-up and studies with larger patient populations are needed to assess the real effectiveness of this technique.

\section{Accelerated corneal crosslinking}

Accelerated CXL was introduced in clinical practice in order to shorten the time required for a CXL procedure. This technique is based on the Bunsen-Roscoe law of photochemical reciprocity. That is, the same photochemical effect can be achieved with reducing the irradiation interval provided that the total energy level is kept constant by a corresponding increase in irradiation intensity [1]. Currently, commercially available ultrafast devices can achieve an irradiance intensity of $43 \mathrm{~mW} /$ $\mathrm{cm}^{2}$. Using this setting, a total treatment time of two minutes is required to achieve a standard Dresden protocol energy dose of $3.4 \mathrm{~J}$ or a radiant exposure of $5.4 \mathrm{~J} / \mathrm{cm}^{2}$ [1]. Several recent in vivo studies using different protocols showed the procedure to be safe and effective in stopping ectasia progression (Table 4) [98-105].

Comparative studies of the effectiveness of the different CXL procedures are described in Table 5 [106-115]. 
Table 2 Outcomes reported in literature for epi-on CXL procedures (2010-2015)

\begin{tabular}{|c|c|c|c|c|c|c|c|}
\hline \multirow[t]{2}{*}{ Author (Year) } & \multirow[t]{2}{*}{ Follow-up } & \multicolumn{3}{|c|}{ Results } & \multirow[t]{2}{*}{ Design } & \multirow[t]{2}{*}{ Number of Eyes } & \multirow[t]{2}{*}{ Indication } \\
\hline & & Kmax & Mean Keratometry & BCVA & & & \\
\hline Lensiak SP et al. (2014) [81] & 6 months & S & & S & PCS & 25 & Keratoconous \\
\hline De Bernardo M et al. (2014) [82] & 6 months & $\mathrm{S}$ & & 1 & PCS & 36 & Keratoconus \\
\hline Khairy HA et al. (2014) [83] & 1 year & D & & S & PCS & 32 & Keratoconus \\
\hline Salman AG (2013) [84] & 1 year & $S$ & & S & PC & 22 & Pediatric Keratoconus \\
\hline Caporossi A et al. (2013) [85] & 2 years & W & & S & PCS & 26 & Keratoconus \\
\hline Buzzonetti L et al. (2012) [86] & 18 months & & W & 1 & PCS & 13 & Pediatric Keratoconus \\
\hline Spadea L et al. (2012) [87] & 1 year & $\mathrm{D}$ & & 1 & PCS & 16 & Keratoconus \\
\hline Filippello M et al. (2012) [88] & 18 months & D & & 1 & PC & 20 & Keratoconus \\
\hline Leccisotti A et al. (2011) [89] & 1 year & S & & । & $\mathrm{RCT}$ & 51 & Keratoconus \\
\hline
\end{tabular}

$S=$ Stabilized, $D=$ Significantly decreased,$I=$ Significantly improved, $W=$ worsened, $P C S=$ Prospective case series, $R C T=$ Randomized controlled trial, $P C=$ Prospective comparative

Surgical protocols reported are very different and unlikely comparable. Also, the follow-up periods are very limited. Therefore, it is very difficult to deduce reliable conclusions. It seems likely that transepithelial CXL, although associated with a lower complication rate, has a lower therapeutic effect than standard CXL and would be ideal for patients with thin corneas, uncooperative individuals, or those with uncertain documented progression. Iontophoresis assisted CXL is a promised technique that could obtain clinical effects similar to those obtainable with a standard technique while maintaining the advantages of epithelium preservation. However, while the basic research results are evident, clinical outcomes are still poor. Accelerated CXL seems to represent a valid strategy to shorten the long treatment time, however the extreme variability of the protocols proposed has not been supported by adequate safety assessment. Well-designed randomized controlled trials comparing traditional CXL and all the alternative procedures are required in order to establish which is the ideal protocol for obtaining the best clinical outcomes and complication profile.

\section{Combined treatments}

\section{CXL and photorefractive keratectomy}

Keratoconus has always been considered a contraindication for PRK. However, during the last few years, the idea of performing PRK in patients with stable keratoconus has been proposed. Consequently, the possibility of combining CXL and PRK was introduced in clinical practice [116-120]. Several clinical reports demonstrated stability in corneas that had undergone a combination of CXL and PRK, either sequentially or combined. Patients experienced improvement in spherical equivalent (SE), defocus equivalent, uncorrected and best corrected visual acuity, high order aberrations and Kmax with stabilization of keratoconus progression during a follow up period of 12-24 months [121-124].

The timing of the ablation treatment and CXL as well as the interval between the two procedures has become topics of discussion. It was reported that patients who underwent both PRK and CXL procedures in the same day obtained better clinical and topographical results with a lower rate of corneal haze, compared to patients treated sequentially [125]. This may be related to the unpredictable refractive outcomes when excimer ablation is performed on cross-linked tissue [126]. However, performing both procedures concurrently in the same day may cause an irregular healing process with the formation of persistent stromal haze, probably related to keratocyte activation, which permanently affects visual performance $[127,128]$.

\section{$C X L$ and intracorneal rings}

Studies reported that CXL halts keratoconus progression, but the overall results in terms of visual rehabilitation were insufficient. On the other hand, intracorneal ring segments (ICRS) produced rapid and substantial improvements of visual parameters but do not stop

Table 3 Outcomes reported in literature for iontophoresis assisted corneal CXL procedures (2014-2015)

\begin{tabular}{|c|c|c|c|c|c|c|}
\hline \multirow[t]{2}{*}{ Author (Year) } & \multirow[t]{2}{*}{ Follow-up } & \multicolumn{2}{|c|}{ Results } & \multirow[t]{2}{*}{ Type } & \multirow[t]{2}{*}{ Number of Eyes } & \multirow[t]{2}{*}{ Indication } \\
\hline & & Kmax & BCVA & & & \\
\hline Buzzonetti L et al. (2015) [95] & 15 months & S & 1 & PCS & 14 & Pediatric Keratoconus \\
\hline Bikbova G et al. (2014) [96] & 1 year & $\mathrm{D}$ & 1 & PCS & 22 & Keratoconus \\
\hline Vinciguerra P et al. (2014) [97] & 1 year & S & । & PCS & 20 & Keratoconus \\
\hline
\end{tabular}

$S=$ Stabilized, $D=$ Significantly decreased, $l=$ Significantly improved, $P C S=$ Prospective case series 
Table 4 Outcomes reported in literature for accelerated corneal CXL procedures (2014-2015)

\begin{tabular}{|c|c|c|c|c|c|c|c|c|}
\hline \multirow[t]{2}{*}{ Author (Year) } & \multirow[t]{2}{*}{ Tecnique } & \multirow[t]{2}{*}{ Follow-up } & \multicolumn{3}{|l|}{ Results } & \multirow[t]{2}{*}{ Type } & \multirow[t]{2}{*}{ Number of Eyes } & \multirow[t]{2}{*}{ Indication } \\
\hline & & & Kmax & $\mathrm{K} 1 / \mathrm{K} 2$ & BCVA & & & \\
\hline Chan TC et al. (2015) [98] & Accelerated & 1 year & $\mathrm{S}$ & & S & PCS & 25 & Keratoconus \\
\hline Ozgurhan EB et al. (2015) [99] & Accelerated & 1 year & $\mathrm{R}$ & & 1 & PCS & 34 & Keratoconus \\
\hline Marino GK et al. (2015) [100] & Accelerated & 2 years & $S$ & & S & PCS & 40 & Post LASIK ectasia \\
\hline Waszczykowska A (2015) [101] & Accelerated & 2 years & $S$ & & S & PCS & 16 & Keratoconus \\
\hline Ozgurhan EB et al. (2014) [102] & Accelerated & 2 years & & $\mathrm{D}$ & I & RCS & 44 & Pediatric Keratoconus \\
\hline Shetty R et al. (2014) [103] & Accelerated & 2 years & - & & 1 & PCS & 18 & Keratoconus \\
\hline Elbaz U et al. (2014) [104] & Accelerated & 1 year & $S$ & & S & PCS & 16 & Keratoconus \\
\hline Cinar $Y$ et al. (2014) [105] & Accelerated & 6 months & D & & I & PCS & 23 & Keratoconus \\
\hline
\end{tabular}

$S=$ Stabilized, $D=$ Significantly decreased, $I=$ Significantly improved, $P C S=$ Prospective case series, $R C S=$ Retrospective case series

progression. Theoretically, a combination of these two procedures can produce better results [1].

Several studies reported concordant results confirming that combining CXL and ICRS implantation improved uncorrected and best corrected visual acuity, refraction, and keratometry during variable follow-up periods (7-12 months) [129-131]. One study reported no difference in topographical or visual outcome after ICRS or ICRS combined with CXL. Thus, the real effect of the combined treatment to the keratoconus progression is still unclear [132].

Moreover, it was reported that after one or both ring explantations, the refractive effects may be stable or reversible while the topographic changes seems to be maintained [133]. Therefore, while collagen crosslinking can be performed before, in conjunction with, or after ICRS implantation, the ideal method for combining these two treatments is still undefined [1].

Table 5 Outcomes reported in literature comparing different CXL procedures (2013-2015)

\begin{tabular}{|c|c|c|c|c|c|c|c|}
\hline \multirow[t]{2}{*}{ Author (Year) } & \multirow{2}{*}{$\begin{array}{l}\text { Techniques } \\
\text { compared }\end{array}$} & \multirow[t]{2}{*}{ Follow-up } & \multicolumn{2}{|l|}{ Results } & \multirow[t]{2}{*}{ Type } & \multirow{2}{*}{$\begin{array}{l}\text { Number } \\
\text { of Eyes }\end{array}$} & \multirow[t]{2}{*}{ Indication } \\
\hline & & & Kmax & BCVA & & & \\
\hline $\begin{array}{l}\text { NG AL et al. } \\
\text { (2015) [106] }\end{array}$ & Standard vs accelerated & 1 year & $\begin{array}{l}\text { Reduction Kmax in standard } \\
\text { group }\end{array}$ & $\begin{array}{l}\text { Improvement BCVA in } \\
\text { standard CXL }\end{array}$ & $\mathrm{CIS}$ & 26 & Keratoconus \\
\hline $\begin{array}{l}\text { Shetty R et al. } \\
\text { (2015) [107] }\end{array}$ & $\begin{array}{l}\text { Standard vs Different } \\
\text { Accelerated Protocols }\end{array}$ & 1 year & $\begin{array}{l}\text { Improvement Kmax in } \\
\text { standard and accelerated } \\
\text { group }\end{array}$ & $\begin{array}{l}\text { Improvement BCVA in } \\
\text { Standard and accelerated } \\
\text { CXL }\end{array}$ & $P R$ & 138 & Keratoconus \\
\hline $\begin{array}{l}\text { Rossi S et al. } \\
\text { (2015) [108] }\end{array}$ & Standard vs TE & 1 year & $\begin{array}{l}\text { Improvement Kmax in } \\
\text { standard and TE CXL }\end{array}$ & $\begin{array}{l}\text { Improvement BCVA in } \\
\text { standard and TE CXL }\end{array}$ & PC & 20 & Keratoconus \\
\hline $\begin{array}{l}\text { Brittingham et al. } \\
\text { (2014) [109] }\end{array}$ & Standard vs accelerated & 1 year & $\begin{array}{l}\text { Stabilization } \mathrm{K} \text { max in } \\
\text { standard CXL }\end{array}$ & & RCS & 131 & Keratoconus \\
\hline $\begin{array}{l}\text { Hashemian H et al. } \\
\text { (2014) [110] }\end{array}$ & Standard vs Accelerated & 15 months & $\begin{array}{l}\text { Improvement Kmax in } \\
\text { standard and accelerated } \\
\text { CXL }\end{array}$ & $\begin{array}{l}\text { Improvement BCVA in } \\
\text { Standard and accelerated } \\
\text { CXL }\end{array}$ & $\mathrm{RCT}$ & 153 & Keratoconus \\
\hline $\begin{array}{l}\text { Sherif AM } \\
\text { (2014) [111] }\end{array}$ & Standard vs Accelerated & 1 year & Stabilization Kmax & $\begin{array}{l}\text { Improvement BCVA in } \\
\text { Standard and accelerated } \\
\text { CXL }\end{array}$ & $\mathrm{RCT}$ & 25 & Keratoconus \\
\hline $\begin{array}{l}\text { Stojanovic A et al. } \\
\text { (2014) [112] }\end{array}$ & Standard vs TE & 1 year & $\begin{array}{l}\text { Stabilization Kmax for } \\
\text { standard and TE CXL }\end{array}$ & $\begin{array}{l}\text { Improvement BCVA in } \\
\text { standard and TE CXL }\end{array}$ & RCT & 40 & Keratoconus \\
\hline $\begin{array}{l}\text { Tomita M et al. } \\
\text { (2014) [113] }\end{array}$ & Standard vs Accelerated & 1 year & $\begin{array}{l}\text { Improvement Kmax in } \\
\text { standard and accelerated } \\
\text { CXL }\end{array}$ & $\begin{array}{l}\text { Improvement BCVA in } \\
\text { Standard and accelerated } \\
\text { CXL }\end{array}$ & $P C$ & 48 & Keratoconus \\
\hline $\begin{array}{l}\text { Cinar Y et al. } \\
\text { (2014) [114] }\end{array}$ & Standard vs Accelerated & 6 months & $\begin{array}{l}\text { Improvement Kmax in } \\
\text { standard and accelerated } \\
\text { CXL }\end{array}$ & $\begin{array}{l}\text { Improvement BCVA in } \\
\text { Standard and accelerated } \\
\text { CXL }\end{array}$ & $P C$ & 26 & Keratoconus \\
\hline $\begin{array}{l}\text { Magli A et al. } \\
\text { (2013) [115] }\end{array}$ & Standard vs TE & 1 year & $\begin{array}{l}\text { Improvement } \mathrm{K} \text { max in } \\
\text { standard and TE CXL }\end{array}$ & $\begin{array}{l}\text { Improvement BCVA in } \\
\text { standard and TE CXL }\end{array}$ & PC & 37 & Keratoconus \\
\hline
\end{tabular}




\section{Alternative uses of corneal crosslinking Infections}

Crosslinking has an antimicrobial effect inherent to UV light interacting with riboflavin as the chromophore. In fact, UV irradiation is used as an antimicrobial procedure for disinfecting water, surfaces and air. It damages both the DNA and RNA of pathogens including bacteria and viruses, and renders them inactive [134].

Additionally, the photoactivated riboflavin seems to produce an antimicrobial effect. In fact, the use of riboflavin as a photosensitizer to inactivate pathogens in plasma, platelet, and red cell products has been described [135].

Due to its nucleic acid specificity and its limited tendency toward indiscriminate oxidation, riboflavin was hypothesized as a photosensitizer for the inactivation of pathogens in infective keratitis. It was reported that riboflavin activated by UVA showed an antimicrobial effect on agar plates inoculated with Pseudomonas aeruginosa, Staphylococcus aureus, Staphylococcus epidermidis, Streptococcus pneumoniae, and Candida albicans. The inhibition of microbial growth was significantly higher in plates treated with UVA activated riboflavin than in those treated with UVA light alone. However, riboflavin alone did not show any significant bactericidal effect [136].

The first reported use of CXL in infective keratitis was in 2008, when Iseli at al. reported healing 4 out of 5 cases of mycobacterial and fungal corneal melting unresponsive to conventional therapy, treated with the standard Dresden protocol [137]. In 2013, Alio et al. in a systematic review and meta-analysis reported similar results [138]. In 2014, Said et al. reported a large prospective clinical trial on infective keratitis comparing 21 eyes treated with CXL in addition to antimicrobial therapy in 19 eyes that received only antimicrobial therapy. They did not find a significant difference between both groups in terms of healing time and final visual acuity. Three patients treated with antimicrobial therapy alone experienced corneal perforation and one an infection relapse while no significant complications occurred in CXL group. The authors conclude that CXL could serve as a valuable adjuvant therapy and may reduce or avoid severe complications preventing the need for emergency keratoplasty [139].

\section{Pseudophakic bullous keratopathy}

In case of corneal edema due to endothelial failure, it has been shown that CXL effect increases corneal resistance to swelling processes. In fact CXL increases the interfiber collagen connections and it's difficult for stromal fluid to separate collagen lamellae and create a potential space for edema accumulation. Therefore, the use of corneal CXL was proposed as an alternative approach for the management of pseudophakic bullous keratopathy (PBK) with the aim to reduce ocular discomfort, improve visual acuity, and delay the need for keratoplasty [140].

Clinical studies evaluating the effectiveness of corneal CXL in the treatment of PBK reported a significant improvement in corneal transparency, corneal thickness, and ocular pain one month postoperatively. However, CXL did not seem to have a long-lasting effect over six months in decreasing pain and maintaining corneal transparency [141, 142].

\section{Conclusions}

At the light of this review we can conclude that there is still much to understand about the real modification of corneal collagen structure after the photochemical CXL reaction. Moreover the constant aim of basic and clinical research today is to identify the best strategies and combination of imbibition and irradiation that can lead to the better clinical efficacy together with the maximum safety of the treatment.

\section{Abbreviations}

CXL: Corneal crosslinking; DALK: Deep anterior lamellar keratoplasty; UVA: Ultraviolet A irradiation; UCVA: Uncorrected visual acuity; BCVA: Bestcorrected visual acuity; D: Diopter; PRK: Photorefractive keratectomy; SE: Spherical equivalent; ICRS: Intracorneal ring segments; PBK: Pseudophakic bullous keratopathy.

\section{Competing interests}

The author declares that he has no competing interests.

Received: 8 September 2015 Accepted: 23 November 2015 Published online: 29 November 2015

\section{References}

1. ASCRS Cornea Clinical Committee. Reshaping procedures for the surgical management of corneal ectasia. J Cataract Refract Surg. 2015;41:842-72.

2. Gordon-Shaag A, Millodot M, Shneor E, Liu Y. The genetic and environmental factors for Keratoconus. Biomed Res Int. 2015;2015:795738. doi:10.1155/2015/795738.

3. Binder PS. Analysis of ectasia after laser in situ keratomileusis: risk factors. J Cataract Refract Surg. 2007:33:1530-8.

4. Chen MC, Lee N, Bourla N, Hamilton DR. Corneal biomechanical measurements before and after laser in situ keratomileusis. J Cataract Refract Surg. 2008;34:1886-91

5. Kirwan C, O'Malley D, O'Keefe M. Corneal hysteresis and corneal resistance factor in keratectasia: finding using the Reichert ocular response analyzer. Ophtalmologica. 2008;222:334-7.

6. Randleman JB, Woodward M, Lynn MJ, Stulting RD. Risk assessment for ectasia after corneal refractive surgery. Ophthalmology. 2008;115:37-50.

7. Vazirani J, Basu S. Keratoconus: current perspectives. Clin Ophthalmol. 2013; 7:2019-30.

8. Ertan A, Colin J. Intracorneal rings for keratoconus and keratectasia. J Cataract Refract Surg. 2007;33(7):1303-14.

9. Raiskup F, Spoerl E. Corneal crosslinking with riboflavin and ultraviolet A. I. Principles. Ocul Surf. 2013;11:65-74.

10. Randleman JB, Khandelwal SS, Hafezi F. Corneal cross-linking. Surv Ophthalmol. 2015;60(6):509-23. doi:10.1016/j.survophthal.2015.04.002.

11. Kamaev P, Friedman MD, Sherr E, Muller D. Photochemical kinetics of corneal cross-linking with riboflavin. Invest Ophthalmol Vis Sci. 2012;53: 2360-7.

12. Wollensak G. Crosslinking treatment of progressive keratoconus: new hope Curr Opin Ophthalmol. 2006;17:356-60.

13. Wollensak G, Spoerl E, Seiler T. Stress-strain measurements of human and porcine corneas after riboflavin-ultraviolet-A-induced cross-linking. J Cataract Refract Surg. 2003;29(9):1780-5. 
14. Kohlhaas M, Spoerl E, Schilde T, Unger G, Wittig C, Pillunat LE. Biomechanical evidence of the distribution of cross-links in corneas treated with riboflavin and ultraviolet A light. J Cataract Refract Surg. 2006;32(2):279-83.

15. Wollensak G, Aurich H, Pham DT, Wirbelauer C. Hydration behavior of porcine cornea crosslinked with riboflavin and ultraviolet A. J Cataract Refract Surg. 2007;33(3):516-21.

16. Wollensak G, Wilsch M, Spoerl E, Seiler T. Collagen fiber diameter in the rabbit cornea after collagen crosslinking by riboflavin/UVA. Cornea. 2004;23(5):503-7.

17. Akhtar S, Almubrad T, Paladini I, Mencucci R. Keratoconus corneal architecture after riboflavin/ultraviolet A cross-linking: ultrastructural studies. Mol Vis. 2013;19:1526-37.

18. Spoerl E, Wollensak G, Seiler T. Increased resistance of crosslinked cornea against enzymatic digestion. Curr Eye Res. 2004;29(1):35-40.

19. Alhayek A, Lu PR. Corneal collagen crosslinking in keratoconus and other eye disease. Int J Ophthalmol. 2015;18(8):407-18.

20. Raiskup F, Spoerl E. Corneal crosslinking with riboflavin and ultraviolet A. Part II. Clinical indications and results. Ocul Surf. 2013;11:93-108.

21. Vinciguerra $P$, Albe $E$, Trazza $S$, Rosetta $P$, Vinciguerra $R$, Seiler $T$, et al. Refractive, topographic, tomographic, and aberrometric analysis of keratoconic eyes undergoing corneal cross-linking. Ophthalmology. 2009; 116:369-78.

22. Wollensak G, Spoerl E, Seiler T. Riboflavin/ultraviolet-a-induced collagen crosslinking for the treatment of keratoconus. Am J Ophthalmol. 2003; 135:620-7.

23. Lang SJ, Messmer EM, Geerling G, Mackert MJ, Brunner T, Dollak S, et al. Prospective, randomized, double-blind trial to investigate the efficacy and safety of corneal cross-linking to halt the progression of keratoconus. BMC Ophthalmol. 2015;15:78.

24. Poli M, Lefevre A, Auxenfans C, Burillon C. Corneal collagen cross-linking for the treatment of progressive Corneal Ectasia: 6-year prospective outcome in a French population. Am J Ophthalmol. 2015;160(4):654-62.

25. De Bernardo M, Capasso L, Lanza M, Tortori A, laccarino S, Cennamo M, et al. Long-term results of corneal collagen crosslinking for progressive keratoconus. J Optom. 2015:8:180-6.

26. McAnena L, O'Keefe M. Corneal collagen crosslinking in children with keratoconus. JAPOS. 2015;19:228-32

27. Sedaghat M, Bagheri M, Ghavami S, Bamdad S. Changes in corneal topography and biomechanical properties after collagen cross linking for keratoconus: 1-year results. Middle East Afr J Ophthalmol. 2015;22:212-9.

28. Khan WA, Zaheer N, Khan S. Corneal collagen cross-linking for keratoconus: results of 3-year follow-up in Pakistani population. Can J Ophthalmol. 2015; 50:143-50.

29. Yildirim A, Cakir H, Kara N, Uslu H, Gurler B, Ozgurhan EB, et al. Corneal collagen crosslinking for ectasia after laser in situ keratomileusis: long-term results. J Cataract Refract Surg. 2014;40:1591-6.

30. Kymionis GD, Grentzelos MA, Liakopoulos DA, Paraskevopoulos TA, Klados $\mathrm{NE}$, Tsoulnaras Kl, et al. Long-term follow-up of corneal collagen crosslinking for keratoconus-the Cretan study. Cornea. 2014;33:1071-9.

31. Kumar Kodavoor S, Arsiwala AZ, Ramamurthy D. One-year clinical study on efficacy of corneal cross-linking in Indian children with progressive keratoconus. Cornea. 2014;33:919-22.

32. Viswanathan D, Kumar NL, Males JJ. Outcome of corneal collagen crosslinking for progressive keratoconus in paediatric patients. Biomed Res Int. 2014;2014:140461. doi:10.1155/2014/140461.

33. Goldich Y, Barkana Y, Wussuku Lior O, Marcovich AL, Hirsh A, Avni I, et al. Corneal collagen cross-linking for the treatment of progressive keratoconus: 3-year prospective outcome. Can J Ophthalmol. 2014:49:54-9.

34. Steinberg J, Ahmadiyar M, Rost A, Frings A, Filev F, Katz T, et al. Anterior and posterior corneal changes after crosslinking for keratoconus. Optom Vis Sci. 2014;91:178-86

35. Wittig-Silva C, Chan E, Islam FM, Wu T, Whiting M, Snibson GR. A randomized, controlled trial of corneal collagen cross-linking in progressive keratoconus: three-year results. Ophthalmology. 2014;121:812-21.

36. Elbaz U, Yeung SN, Ziai S, Lichtinger AD, Zauberman NA, Goldich Y, et al Collagen crosslinking after radial keratotomy. Cornea. 2014;33:131-6.

37. Ghanem RC, Santhiago MR, Berti T, Netto MV, Ghanem VC. Topographic, corneal wavefront, and refractive outcomes 2 years after collagen crosslinking for progressive keratoconus. Cornea. 2014;33:43-8.

38. Toprak I, Yildirim C. Effects of corneal collagen crosslinking on corneal topographic indices in patients with keratoconus. Eye Contact Lens. 2013;39:385-7.
39. Hashemi H, Seyedian MA, Miraftab M, Fotouhi A, Asgari S. Corneal collagen cross-linking with riboflavin and ultraviolet a irradiation for keratoconus: long-term results. Ophthalmology. 2013;120:1515-20.

40. Richoz O, Mavrakanas N, Pajic B, Hafezi F. Corneal collagen cross-linking for ectasia after LASIK and photorefractive keratectomy: long-term results. Ophthalmology. 2013;120:1354-9.

41. Ivarsen A, Hjortdal J. Collagen cross-linking for advanced progressive keratoconus. Cornea. 2013;32:903-6.

42. Legare ME, lovieno A, Yeung SN, Kim P, Lichtinger A, Hollands S, et al. Corneal collagen cross-linking using riboflavin and ultraviolet $A$ for the treatment of mild to moderate keratoconus: 2-year follow-up. Can J Ophthalmol. 2013;48:63-8.

43. O'Brart DP, Kwong TQ, Patel P, McDonald RJ, O'Brart NA. Long-term follow-up of riboflavin/ultraviolet A (370 nm) corneal collagen cross-linking to halt the progression of keratoconus. Br J Ophthalmol. 2013;97:433-7.

44. Arora R, Gupta D, Goyal JL, Jain P. Results of corneal collagen cross-linking in pediatric patients. J Refract Surg. 2012;28:759-62.

45. Chatzis N, Hafezi F. Progression of keratoconus and efficacy of pediatric [corrected] corneal collagen cross-linking in children and adolescents. J Refract Surg. 2012;28:753-8.

46. Vinciguerra R, Romano MR, Camesasca Fl, Azzolini C, Trazza S, Morenghi E, et al. Corneal cross-linking as a treatment for keratoconus: four-year morphologic and clinical outcomes with respect to patient age. Ophthalmology. 2013;120:908-16.

47. Viswanathan D, Males J. Prospective longitudinal study of corneal collagen cross-linking in progressive keratoconus. Clin Experiment Ophthalmol. 2013;41:531-6.

48. Poli M, Cornut PL, Balmitgere T, Aptel F, Janin H, Burillon C. Prospective study of corneal collagen cross-linking efficacy and tolerance in the treatment of keratoconus and corneal ectasia: 3-year results. Cornea. 2013; 32:583-90.

49. Lamy R, Netto CF, Reis RG, Procopio B, Porco TC, Stewart JM, et al. Effects of corneal cross-linking on contrast sensitivity, visual acuity, and corneal topography in patients with keratoconus. Cornea. 2013;32:591-6.

50. Kránitz K, Kovács I, Miháltz K, Sándor GL, Knorz MC, Németh J, et al. Corneal changes in progressive keratoconus after cross-linking assessed by Scheimpflug camera. J Refract Surg. 2012;28:645-9.

51. Guber I, Guber J, Kaufmann C, Bachmann LM, Thiel MA. Visual recovery after corneal crosslinking for keratoconus: a 1-year follow-up study. Graefes Arch Clin Exp Ophthalmol. 2013;251:803-7.

52. Vinciguerra P, Albé E, Frueh BE, Trazza S, Epstein D. Two-year corneal crosslinking results in patients younger than 18 years with documented progressive keratoconus. Am J Ophthalmol. 2012;154:520-6.

53. Caporossi A, Mazzotta C, Baiocchi S, Caporossi T, Denaro R, Balestrazzi A. Riboflavin-UVA-induced corneal collagen cross-linking in pediatric patients. Cornea. 2012;31:227-31.

54. Goldich Y, Marcovich AL, Barkana Y, Mandel Y, Hirsh A, Morad Y, et al. Clinical and corneal biomechanical changes after collagen cross-linking with riboflavin and UV irradiation in patients with progressive keratoconus: results after 2 years of follow-up. Cornea. 2012;31:609-14.

55. Asri D, Touboul D, Fournié P, Malet F, Garra C, Gallois A, et al. Corneal collagen crosslinking in progressive keratoconus: multicenter results from the French National Reference Center for Keratoconus. J Cataract Refract Surg. 2011;37:2137-43.

56. Fuentes-Páez G, Castanera F, Gómez de Salazar-Martinez R, Salas JF, Izquierdo E. Corneal cross-linking in patients with radial keratotomy: shortterm follow-up. Cornea. 2012;31:232-5.

57. Kymionis GD, Portaliou DM, Diakonis VF, Kounis GA, Panagopoulou SI, Grentzelos MA. Corneal collagen cross-linking with riboflavin and ultraviolet-A irradiation in patients with thin corneas. Am J Ophthalmol. 2012;153:24-8.

58. Koller T, Pajic B, Vinciguerra P, Seiler T. Flattening of the cornea after collagen crosslinking for keratoconus. J Cataract Refract Surg. 2011;37:1488-92.

59. Greenstein SA, Fry KL, Hersh PS. Corneal topography indices after corneal collagen crosslinking for keratoconus and corneal ectasia: one-year results. J Cataract Refract Surg. 2011:37:1282-90.

60. Raiskup F, Spoerl E. Corneal cross-linking with hypo-osmolar riboflavin solution in thin keratoconic corneas. Am J Ophthalmol. 2011;152:28-32.

61. Hersh PS, Greenstein SA, Fry KL. Corneal collagen crosslinking for keratoconus and corneal ectasia: One-year results. J Cataract Refract Surg. 2011;37:149-60. 
62. Salgado JP, Khoramnia R, Lohmann CP, Winkler von Mohrenfels C. Corneal collagen crosslinking in post-LASIK keratectasia. Br J Ophthalmol. 2011;95:493-7.

63. Caporossi A, Mazzotta C, Baiocchi S, Caporossi T. Long-term results of riboflavin ultraviolet a corneal collagen cross-linking for keratoconus in Italy: the Siena eye cross study. Am J Ophthalmol. 2010;149:585-93.

64. Vinciguerra $P$, Albè E, Trazza $S$, Seiler T, Epstein D. Intraoperative and postoperative effects of corneal collagen cross-linking on progressive keratoconus. Arch Ophthalmol. 2009;127:1258-65.

65. Vinciguerra P, Camesasca Fl, Albè E, Trazza S. Corneal collagen cross-linking for ectasia after excimer laser refractive surgery: 1-year results. J Refract Surg. 2010;26:486-97.

66. Shalchi Z, Wang X, Nanavaty MA. Safety and efficacy of epithelium removal and transepithelial corneal collagen crosslinking for keratoconus. Eye (Lond). 2015:29:15-29.

67. Craig JA, Mahon J, Yellowlees A, Barata T, Glanville J, Arber M, et al. Epithelium-off photochemical corneal collagen cross-linkage using riboflavin and ultraviolet a for keratoconus and keratectasia: a systematic review and meta-analysis. Ocul Surf. 2014;12:202-14.

68. Greenstein SA, Fry KL, Bhatt J, Hersh PS. Natural history of corneal haze after collagen crosslinking for keratoconus and corneal ectasia: Scheimpflug and biomicroscopic analysis. J Cataract Refract Surg. 2010;36:2105-14.

69. Mastropasqua L, Nubile M, Lanzini M, Calienno R, Mastropasqua R, Agnifili L, et al. Morphological modification of the cornea after standard and transepithelial corneal cross-linking as imaged by anterior segment optical coherence tomography and laser scanning in vivo confocal microscopy. Cornea. 2013;32:855-61.

70. Abbouda A, Abicca I, Alio JL. Infectious keratitis following corneal crosslinking: a systematic review of reported cases: management, visual outcome, and treatment proposed. Semin Ophthalmol. 2014;13:1-7.

71. Kymionis GD, Bouzoukis DI, Diakonis VF, Portaliou DM, Pallikaris Al, Yoo SH. Diffuse lamellar keratitis after corneal crosslinking in a patient with post-laser in situ keratomileusis corneal ectasia. J Cataract Refract Surg. 2007;33:2135-7.

72. Ferrari G, luliano L, Viganò M, Rama P. Impending corneal perforation after collagen cross-linking for herpetic keratitis. J Cataract Refract Surg. 2013;39: 638-41.

73. Sharma A, Nottage JM, Mirchia K, Sharma R, Mohan K, Nirankari VS. Persistent corneal edema after collagen cross-linking for keratoconus. Am J Ophthalmol. 2012;154:922-6.

74. Mannermaa E, Vellonen KS, Urtti A. Drug transport in corneal epithelium and blood-retina barrier: emerging role of transporters in ocular pharmacokinetics. Adv Drug Deliv Rev. 2006;58:1136-63.

75. Baiocchi S, Mazzotta C, Cerretani D, Caporossi T, Caporossi A. Corneal crosslinking: riboflavin concentration in corneal stroma exposed with and without epithelium. J Cataract Refract Surg. 2009;35:893-9.

76. Abdelghaffar W, Hantera M, Elsabagh H. Corneal collagen cross-linking: promises and problems. Br J Ophthalmol. 2010;94:1559-60.

77. Ashwin PT, McDonnell PJ. Collagen cross-linkage: a comprehensive review and directions for future research. Br J Ophthalmol. 2010;94:965-70.

78. Torricelli AA, Ford MR, Singh V, Santhiago MR, Dupps WJ, Wilson SE. BAC-EDTA transepithelial riboflavin-UVA crosslinking has greater biomechanical stiffening effect than standard epithelium-off in rabbit corneas. Exp Eye Res. 2014;125:114-7.

79. Rechichi M, Daya S, Scorcia V, Meduri A, Scorcia G. Epithelial-disruption collagen crosslinking for keratoconus: one-year results. J Cataract Refract Surg. 2013;39:1171-8.

80. Acar BT, Utine CA, Ozturk V, Acar S, Ciftci F. Can the effect of transepithelial corneal collagen cross-linking be improved by increasing the duration of topical riboflavin application? An in vivo confocal microscopy study. Eye Contact Lens. 2014;40(4):207-12.

81. Lesniak SP, Hersh PS. Transepithelial corneal collagen crosslinking for keratoconus: six-month results. J Cataract Refract Surg. 2014;40:1971-9.

82. De Bernardo M, Capasso L, Tortori A, Lanza M, Caliendo L, Rosa N. Trans epithelial corneal collagen crosslinking for progressive keratoconus: 6 months follow up. Cont Lens Anterior Eye. 2014;37:438-41.

83. Khairy HA, Marey HM, Ellakwa AF. Epithelium-on corneal cross-linking treatment of progressive keratoconus: a prospective, consecutive study. Clin Ophthalmol. 2014;8:819-23.

84. Salman AG. Transepithelial corneal collagen crosslinking for progressive keratoconus in a pediatric age group. J Cataract Refract Surg. 2013;39:1 164-70.

85. Caporossi A, Mazzotta C, Paradiso AL, Baiocchi S, Marigliani D, Caporossi T. Transepithelial corneal collagen crosslinking for progressive keratoconus: 24-month clinical results. J Cataract Refract Surg. 2013;39:1157-63.
86. Buzzonetti L, Petrocelli G. Transepithelial corneal cross-linking in pediatric patients: early results. J Refract Surg. 2012;28:763-7.

87. Spadea L, Mencucci R. Transepithelial corneal collagen cross-linking in ultrathin keratoconic corneas. Clin Ophthalmol. 2012;6:1785-92.

88. Filippello M, Stagni E, O'Brart D. Transepithelial corneal collagen crosslinking: bilateral study. J Cataract Refract Surg. 2012;38:283-91.

89. Leccisotti A, Islam T. Transepithelial corneal collagen cross-linking in keratoconus. J Refract Surg. 2010;26:942-8

90. Mastropasqua L, Lanzini M, Curcio C, Calienno R, Mastropasqua R, Colasante $M$, et al. Structural modifications and tissue response after standard epi-off and iontophoretic corneal crosslinking with different irradiation procedures. Invest Ophthalmol Vis Sci. 2014;55:2526-33.

91. Mastropasqua L, Nubile M, Calienno R, Mattei PA, Pedrotti E, Salgari N, et al. Corneal cross-linking: intrastromal riboflavin concentration in iontophoresisassisted imbibition versus traditional and transepithelial techniques. Am J Ophthalmol. 2014;157:623-30.

92. Mencucci R, Ambrosini S, Paladini I, Favuzza E, Boccalini C, Raugei G, et al. Early effects of corneal collagen cross-linking by iontophoresis in ex vivo human corneas. Graefes Arch Clin Exp Ophthalmol. 2015:253:277-86.

93. Cassagne M, Laurent C, Rodrigues M, Galinier A, Spoerl E, Galiacy SD, et al. Iontophoresis transcorneal delivery technique for transepithelial corneal collagen crosslinking with riboflavin in a rabbit model. Invest Ophthalmol Vis Sci. 2014. doi:10.1167/iovs.13-12595.

94. Lombardo M, Serrao S, Rosati M, Ducoli P, Lombardo G. Biomechanical changes in the human cornea after transepithelial corneal crosslinking using iontophoresis. J Cataract Refract Surg. 2014;40:1706-15.

95. Buzzonetti L, Petrocelli G, Valente P, larossi G, Ardia R, Petroni S. Iontophoretic transepithelial corneal cross-linking to halt keratoconus in pediatric cases: 15-month follow-up. Cornea. 2015;34:512-5

96. Bikbova G, Bikbov M. Transepithelial corneal collagen cross-linking by iontophoresis of riboflavin. Acta Ophthalmol. 2014;92:30-4.

97. Vinciguerra P, Randleman JB, Romano V, Legrottaglie EF, Rosetta P, Camesasca $\mathrm{Fl}$, et al. Transepithelial iontophoresis corneal collagen cross-linking for progressive keratoconus: initial clinical outcomes. J Refract Surg. 2014;30:746-53.

98. Chan TC, Chow WW, Jhanji V, Wong WW. Different topographic response between mild to moderate and advanced keratoconus after accelerated collagen cross-linking. Cornea. 2015;34:922-7.

99. Ozgurhan EB, Akcay BI, Kurt T, Yildirim Y, Demirok A. Accelerated corneal collagen cross-linking in thin keratoconic corneas. J Refract Surg. 2015; 31:386-90.

100. Marino GK, Torricelli AA, Giacomin N, Santhiago MR, Espindola R, Netto MV Accelerated corneal collagen cross-linking for postoperative LASIK Ectasia: two-year outcomes. J Refract Surg. 2015;31:380-4.

101. Waszczykowska A, Jurowski P. Two-year accelerated corneal cross-linking outcome in patients with progressive keratoconus. Biomed Res Int. 2015; 2015:325157. doi:10.1155/2015/325157

102. Ozgurhan EB, Kara N, Cankaya Kl, Kurt T, Demirok A. Accelerated corneal cross-linking in pediatric patients with keratoconus: 24-month outcomes. J Refract Surg. 2014;30:843-9.

103. Shetty R, Nagaraja H, Jayadev C, Pahuja NK, Kurian Kummelil M, Nuijts RM. Accelerated corneal collagen cross-linking in pediatric patients: two-year follow-up results. Biomed Res Int. 2014;2014:894095. doi:10.1155/2014/ 894095.

104. Elbaz U, Shen C, Lichtinger A, Zauberman NA, Goldich Y, Chan CC, et al. Accelerated (9-mW/cm2) corneal collagen crosslinking for keratoconus-A 1-year follow-up. Cornea. 2014;33:769-73.

105. Cınar Y, Cingü AK, Turkcu FM, Yüksel H, Sahin A, Yıldırım A, et al. Accelerated corneal collagen cross-linking for progressive keratoconus Cutan Ocul Toxicol. 2014;33:168-71.

106. Ng AL, Chan TC, Cheng AC. Conventional versus accelerated corneal collagen cross-linking in the treatment of keratoconus. Clin Experiment Ophthalmol. 2015. doi:10.1111/ceo.12571.

107. Shetty R, Pahuja NK, Nuijts RM, Ajani A, Jayadev C, Sharma C, et al. Current protocols of corneal collagen cross-linking: visual, refractive, and tomographic outcomes. Am J Ophthalmol. 2015;160:243-9.

108. Rossi S, Orrico A, Santamaria C, Romano V, De Rosa L, Simonelli F, et al. Standard versus trans-epithelial collagen cross-linking in keratoconus patients suitable for standard collagen cross-linking. Clin Ophthalmol. 2015;9:503-9.

109. Brittingham S, Tappeiner C, Frueh BE. Corneal cross-linking in keratoconus using the standard and rapid treatment protocol: differences in 
demarcation line and 12-month outcomes. Invest Ophthalmol Vis Sci. 2014; 55:8371-6.

110. Hashemian H, Jabbarvand M, Khodaparast M, Ameli K. Evaluation of corneal changes after conventional versus accelerated corneal cross-linking: a randomized controlled trial. J Refract Surg. 2014;30:837-42.

111. Sherif AM. Accelerated versus conventional corneal collagen cross-linking in the treatment of mild keratoconus: a comparative study. Clin Ophthalmol. 2014;8:1435-40.

112. Stojanovic A, Zhou W, Utheim TP. Corneal collagen cross-linking with and without epithelial removal: a contralateral study with $0.5 \%$ hypotonic riboflavin solution. Biomed Res Int. 2014;2014:619398. doi:10.1155/2014/619398.

113. Tomita M, Mita M, Huseynova T. Accelerated versus conventional corneal collagen crosslinking. J Cataract Refract Surg. 2014;40:1013-20.

114. Cınar Y, Cingü AK, Türkcü FM, Çınar T, Yüksel H, Özkurt ZG, et al. Comparison of accelerated and conventional corneal collagen cross-linking for progressive keratoconus. Cutan Ocul Toxicol. 2014;33:218-22.

115. Magli A, Forte R, Tortori A, Capasso L, Marsico G, Piozzi E. Epithelium-off corneal collagen cross-linking versus transepithelial cross-linking for pediatric keratoconus. Cornea. 2013;32:597-601.

116. Alpins N, Stamatelatos G. Customized photoastigmatic refractive keratectomy using combined topographic and refractive data for myopia and astigmatism in eyes with forme fruste and mild keratoconus. J Cataract Refract Surg. 2007; 33:591-602.

117. Chelala E, Rami HE, Dirani A, Fadlallah A, Fakhoury O, Warrak E. Photorefractive keratectomy in patients with mild to moderate stable keratoconus: A five-year prospective follow-up study. Clin Ophthalmol. 2013;7:1923-8.

118. Guedj M, Saad A, Audureau E, Gatinel D. Photorefractive keratectomy in patients with suspected keratoconus: Five-year follow-up. J Cataract Refract Surg. 2013;39:66-73.

119. Cennamo G, Intravaja A, Boccuzzi D, Marotta G, Cennamo G. Treatment of keratoconus by topography-guided customized photorefractive keratectomy: Two-year follow-up study. J Refract Surg. 2008;24:145-9.

120. Bilgihan K, Ozdek SC, Konuk O, Akata F, Hasanreisoglu B. Results of photorefractive keratectomy in keratoconus suspects at 4 years. J Refract Surg. 2000;16:438-43.

121. Stojanovic A, Zhang J, Chen X, Nitter TA, Chen S, Wang Q. Topographyguided transepithelial surface ablation followed by corneal collagen crosslinking performed in a single combined procedure for the treatment of keratoconus and pellucid marginal degeneration. J Refract Surg. 2010;26: 145-52.

122. Kymionis GD, Kontadakis GA, Kounis GA, Portaliou DM, Karavitaki AE, Magarakis $\mathrm{M}$, et al. Simultaneous topography-guided PRK followed by corneal collagen cross-linking for keratoconus. J Refract Surg. 2009;25:S807-11.

123. Alessio G, L'Abbate M, Sborgia C, La Tegola MG. Photorefractive keratectomy followed by cross-linking versus cross-linking alone for management of progressive keratoconus: two-year follow-up. Am J Ophthalmol. 2013;155:54-65.

124. Fadlallah A, Dirani A, Chelala E, Antonios R, Cherfan G, Jarade E. Nontopography-guided PRK combined with CXL for the correction of refractive errors in patients with early stage keratoconus. J Refract Surg. 2014;30:688-93.

125. Kanellopoulos AJ, Binder PS. Collagen cross-linking (CCL) with sequential topography-guided PRK; a temporizing alternative for keratoconus to penetrating keratoplasty. Cornea. 2007;26:891-5.

126. Güell $J$, Verdaguer $P$, Elies D, Gris O, Manero F. Persistent stromal scar after PRK and CXL: different preoperative findings, similar complication. J Refract Surg. 2015;31:211-2.

127. Kymionis GD, Portaliou DM, Diakonis VF, Kontadakis GA, Krasia MS, Papadiamantis AG, et al. Posterior linear stromal haze formation afte simultaneous photorefractive keratectomy followed by corneal collagen cross-linking. Invest Ophthalmol Vis Sci. 2010;51:5030-3.

128. Güell JL, Verdaguer P, Elies D, Gris O, Manero F. Late onset of a persistent, deep stromal scarring after PRK and corneal cross-linking in a patient with forme fruste keratoconus. J Refract Surg. 2014;30:286-8.

129. Saelens IEY, Bartels MC, Bleyen I, Van Rij G. Refractive, topographic, and visual outcomes of same-day corneal cross-linking with Ferrara intracorneal ring segments in patients with progressive keratoconus. Cornea. 2011;30: 1406-8.

130. Kılıç A, Kamburoglu G, Akıncı A. Riboflavin injection into the corneal channel for combined collagen crosslinking and intrastromal corneal ring segment implantation. J Cataract Refract Surg. 2012;38:878-83.
131. Coskunseven E, Jankov II MR, Hafezi F, Atun S, Arslan E, Kymionis GD. Effect of treatment sequence in combined intrastromal corneal rings and corneal collagen crosslinking for keratoconus. J Cataract Refract Surg. 2009;35:2084-91.

132. Çakir H, Pekel G, Perente I, Genç S. Comparison of intrastromal corneal ring segment implantation only and in combination with collagen crosslinking for keratoconus. Eur J Ophthalmol. 2013;23:629-34.

133. Yeung SN, Lichtinger A, Ku JY, Kim P, Low SA, Rootman DS. Intracorneal ring segment explantation after intracorneal ring segment implantation combined with same-day corneal collagen crosslinking in keratoconus. Cornea. 2013:32:1617-20.

134. Tabibian D, Richoz O, Hafezi F. PACK-CXL: Corneal Cross-linking for Treatment of Infectious Keratitis. J Ophthalmic Vis Res. 2015;10:77-80.

135. Goodrich RP. The use of riboflavin for inactivation of pathogens in blood products. Vox Sang. 2000;78:211-5.

136. Martins SA, Combs JC, Noguera G, Camacho W, Wittmann P, Walther R, et al. Antimicrobial efficacy of riboflavin/UVA combination $(365 \mathrm{~nm})$ in vitro for bacterial and fungal isolates: a potential new treatment for infectious keratitis. Invest Ophthalmol Vis Sci. 2008;49(8):3402-8.

137. Iseli HP, Thiel MA, Hafezi F, Kampmeier J, Seiler T. Ultraviolet A/riboflavin corneal cross-linking for infectious keratitis associated with corneal melts. Cornea. 2008;27:590-4.

138. Alio JL, Abbouda A, Valle DD, Del Castillo JM, Fernandez JA. Corneal cross linking and infectious keratitis: a systematic review with a meta-analysis of reported cases. J Ophthalmic Inflamm Infect. 2013;3:47.

139. Said DG, Elalfy MS, Gatzioufas Z, El-Zakzouk ES, Hassan MA, Saif MY, et al. Collagen cross-linking with photoactivated riboflavin (PACK-CXL) for the treatment of advanced infectious keratitis with corneal melting. Ophthalmology. 2014;121:1377-82.

140. Sorkin N, Varssano D. Corneal collagen crosslinking: a systematic review. Ophthalmologica. 2014;232:10-27.

141. Ghanem RC, Santhiago MR, Berti TB, Thomaz S, Netto MV. Collagen crosslinking with riboflavin and ultraviolet-A in eyes with pseudophakic bullous keratopathy. J Cataract Refract Surg. 2010;36:273-6.

142. Sharma N, Roy S, Maharana PK, Sehra SV, Sinha R, Tandon R, et al. Outcomes of corneal collagen crosslinking in pseudophakic bullous keratopathy. Cornea. 2014;33:243-6.

\section{Submit your next manuscript to BioMed Central and we will help you at every step:}

- We accept pre-submission inquiries

- Our selector tool helps you to find the most relevant journal

- We provide round the clock customer support

- Convenient online submission

- Thorough peer review

- Inclusion in PubMed and all major indexing services

- Maximum visibility for your research

Submit your manuscript at www.biomedcentral.com/submit 